\title{
Progress in Sorghum Head Smut Research
}

\author{
Chunming Bai ${ }^{1, b}$, Yifei $\mathrm{Liu}^{2, \mathrm{~b}}$, Xiaochun $\mathrm{Lu}^{1}$ and Chengguang Tao ${ }^{1, \mathrm{a},{ }^{\star}}$ \\ ${ }^{1}$ Liaoning Academy of Agricultural Sciences, Shenyang, 110161, China \\ ${ }^{2}$ Shenyang Agricultural University, Shenyang, 110161, China \\ a Corresponding author's email: laast@vip.sina.com, \\ b Joint first authors' email: baichunming82@163.com and liuyifeiscience@163.com, \\ * Corresponding author
}

\begin{abstract}
Keywords: Sorghum, Head Smut, Genetic Traits, Resistance Mechanism.
Abstract. Sorghum of the family Peaceae [Sorghum bicolor $(L)$ Moench] is an important crop grown worldwide. Sorghum head smut [Sporisorium reilianum (Kühn) Langdon \& Fullerton] is one of major diseases in sorghum production. That are reviewed from the following several aspects of the problem such as the incidence, hazards and physiological race variations of sorghum head smut, the genetic Traits and gene mapping of sorghum resistance to head smut and the research progress on sorghum resistance mechanism to sporisorium reiliana. It is summarized that fine mapping and cloning for sorghum genetic resistance to head smut not only help to employ molecular markers to improve resistance breeding efficiency, but also prove favorable to immune molecular mechanism study on head smut.
\end{abstract}

\section{Introduction}

Sorghum of the family Peaceae [Sorghum bicolor $(L)$ Moench] also known as durra, is the key food crop and forage crop in the world. Due to its numerous superior qualities such as stress resistance and good heterosis for its high photosynthetic efficiency as C4 plant, drought-resistance, flood-resistance and salt resistance, it is referred as "life-saving grain" in African arid regions. The main sorghum-growing regions are located in tropical arid areas and semi-arid areas in Asia, Africa and America. The sorghum culture in China enjoys a long history, at least over 5000 years old as the earliest history books have supported. Moreover, China is one of the key nations with the largest sorghum acreage worldwide. Sorghum is not only served as human food, but also as forage in animal husbandry. Additionally, it is consumed in brewery as an important raw material. Sorghum head smut [Sporisorium reilianum (Kühn Langdon \& Fullerton] is one of major diseases in sorghum production. Over the recent years, with planting acreage expansion, changes in sorghum cultivation practice and pervasive continuous cropping, field bacterium source is under substantial accumulation, and soil-borne diseases, sorghum head smut for instance, have markedly aggravated, so sorghum industry development is seriously restricted, which turns out to be an urgent problem in sorghum production.

\section{Incidence, Hazards and Physiological Race Variations of Sorghum Head Smut}

Sorghum head smut, caused by Sporisorium reilianum [Sporisorium reilianum (Kühn) Langdon \& Fullerton] (Fungi kingdom, Basidiomycota, Sporisorium genus), is one of primary soil-borne fungal diseases for sorghum [1]. The sites of infection for the sorghum seedlings are mesocotyl, followed by coleoptile and radicle as well. The major infection stage is the period prior to seedling emergence. The factors closely related to sorghum head smut incidence include levels of bacteria in soil, soil moisture and temperature, sowing depth, emergence speed and cultivars resistance and the similar.

When the hyphae of Sporisorium reilianum invade the sorghum from the roots successfully, they will be insidious over the whole growth period, not attributable to any fatal damage to their host. During the pathogenic bacteria incubation period, there are no visible symptoms from the sorghum plants, whereas as ear and tassel differentiation period approaches, those insidious hyphae begin to proliferate heavily, and then typical smut disease is observed on the ears of sorghum in the end [2]. 
Since such a disease is able to destroy sorghum ears straightway, it proves to be serious threats to sorghum production. The outbreak of sorghum head smut in 1990s was initiated by Race 3 of Sporisorium reilianum, with an incidence area of 58 thousand hectars, average incidence rate of 18\% to a higher one up to more than $80 \%$, and the grain loss for 54 thousand tons. Therefore, the sorghum head smut control is of great importance to safe production for sorghum [3]. Currently, six physiological races of Sporisorium reilianum are in USA with their major differential hosts as Tx7078, SA281, Tx414 and TAM2571 [4], three races in Mexico [5] and four races in China [6]. There are marked difference in pathogenicity among those physiological races [7]. Race 1 is highly pathogenic to Chinese sorghum "Sanchisan" and "Husihao", while less pathogenic to sweet sorghum Sumac, and almost non-infective to white Caffrorum and Tx3197A; Race 2 is highly pathogenic to Tx3197A, white Caffrorum and sweet sorghum Sumac, while less pathogenic to Chinese sorghum and sweet corns. Race 3, as highly pathogenic, is able to infect Tx622A and Tx622B, which are not infected by Race 1 and Race 2 though (selected as the differential hosts), so this proves that Chinese physiological races are of the entirely different virulence traits from American ones. Race 4 is highly pathogenic to A2V4 and Jinza 12, while non-infective to 7501B, Tx7078, B35, which are infected by Race 3 though. There are fewer breeding materials with immunity or high resistance to all these four races [6].

As observed from the research findings above, the physiological races of sorghum are featured by simple differentiation, with different disease resistance from different races. Resistance to sorghum head smut is likely to coincide with one-to-one genetic relationships, a fact more favorable to application of molecular mark assisted breeding and molecular breeding technology for sorghum resistance to head smut, and this shall improve breeding productivity and safe production. Therefore, fine mapping and cloning of sorghum resistant genes to head smut are of key significance to resistant varieties cultivation and safe production for sorghum.

\section{Genetic Traits and Gene Mapping of Sorghum Resistance to Head Smut}

The genetic traits of sorghum resistance to head smut shall determine gene mapping complexity. This is adopted Race 1 of artificial inoculation in their genetic resistance study on head smut, according to incomplete diallel cross design for 17 varieties (strains) with different resistance. The results indicated that genetic resistance to head smut varied from varieties to varieties for sorghum, of which some varieties (strains) were characterized by quantitative genetic traits, while some by qualitative genetic traits. As for resistant varieties (strains) were of quantitative genetic traits, their resistance was mostly regulated by additive genes. That is adopted six sorghum germplasms with different resistance for an incomplete diallel cross design, and they studied sorghum resistance genes to Race 3 of Sporisorium reiliana. As the results indicated, resistance genes and susceptibility genes for most test materials were regulated by qualitative traits, and only if a single parent is immune, then F1 showed immunity or high resistance, possible on account of effects from 1 2 couples of non-allelic major genes, along with additive effects from some minor genes. Oh and others (1994) adopted F2 and F3 hybrid materials of SC325×RTx7078. They also employed RFLP and RAPD technology and introduced molecular marker for the resistance locus of Shsl for Race 5, the Sporisorium reiliana of American sorghum. It was discovered that it was linked to RFLP locus of pSbTXS560 and pSbTXS1294, as well as RAPD locus of OPG5, and then it was pinpointed at $94.1 \mathrm{cM}$ from No.8 chromosome. The genetic resistance study results by Zou Jianqiu are similar to those above. SSR technology and bulked segregation analysis methodology were used, with segregation population of restorer line (2381R/Aisi) and segregation population of maintainer line (Tx622B/7050B) adopted respectively as well [8]. Then gene molecular markers resistant to Race 3 of Sporisorium reiliana were screened, from which two gene markers were obtained. Since they stably appeared among these resistant varieties, they, namely Xtxp13 and Xtxp145, were regarded as SSR markers in gene markers resistant to Race 3 of sorghum Sporisorium reiliana. These two markers were located at No.2 chromosome and No. 9 chromosome respectively, with genetic distance of 9.6 and 10.4 cM roughly from resistance locus separately. It was deemed that resistance to Race 3 of sorghum Sporisorium 
reiliana was regulated by two couples of non-allelic genes, which were independent of each other, and there may be some interaction effects among genes.

Based on the existing research, though most reports on genetic resistance to sorghum head smut are merely of qualitative traits, mapping reliability and elaboration still remain to be improved, for there are great defects in gene mapping markers for head smut, in colony and disease resistance evaluation as well. As a result, it is imperative to conduct finer mapping for the genetic resistance to sorghum head smut.

\section{Research Progress on Sorghum Resistance Mechanism to Sporisorium Reiliana}

There are two patterns in plant molecular immune system. One is PTI (PAMPs-triggered immunity) by recognition of immune responses from receptors, or PRR (pattern recognition receptor), and the other one is ETI (Effector-triggered immunity) by recognition of immune responses from pathogen effector protein. PTI system covers immune responses from bacterial flagellum, elongation factor EF-Tu, together with fungal chitin, oligogalacturonide acid, keratin monomer and systemin or the similar. As for ETI system, when pathogenic bacteria infection occurs in plants, pathogenic bacteria shall secrete effector protein inside the plant cells, and the effector protein shall inhibit plant PTI, so that pathogenic bacteria shall avoid plant immune responses to enhance their pathogenicity [9]. What is genetically encoded as $\mathrm{R}$ for plants is basically intracellular receptor protein of NBS-LRRNBS-LRR type, which is able to recognize effector protein as secreted from different sources of pathogenic bacteria, and this shall possibly result in ETI disease resistance. The molecular mechanism for sorghum resistant to head smut is not as obvious as expected, and there are no reports on resistance genes cloning. However, in case of race specificity for sorghum head smut, it is likely that resistance to these four Chinese races shall be included in ETI resistance system. The genetic resistance to corn head smut is of quantitative traits. As indicated from genetic resistance to head smut for cloned corns, such a gene as ZmWAK is a type of transmembrane kinase protein, which acts as receptor kinase to transmit outside signals within plant cells. WAK is likely to be regarded as receptor-like kinase, so it may "monitor” pectin integrity and recognize DAMPs (damage-associated molecular patterns) from plant cells when pathogenic bacteria attack cell wall, and then it shall induce ETI resistance responses furthermore [10]. Though sorghum shares homeotic genes (sb05g027230) with corn genetic resistance of ZmWAK to head smut, but Sporisorium reilianum experiences different pathogenicity from Sphacelotheca reiliana, both of which are two types of physiological differentiation of the same species though. The mycelium in the corns is not able to invade sorghum, and Sporisorium reilianum may invade corns, whereas its invasiveness is rather low, so such genes are not applied to describe molecular mechanism of sorghum resistance to head smut. There are more than 200 resistance genes for sorghum NBS- LRR [11], but there have been no reports on whether these NBS genes are related with resistance to head smut so far.

\section{Summary}

Therefore, fine mapping and cloning for sorghum genetic resistance to head smut not only help to employ molecular markers to improve resistance breeding efficiency, but also prove favorable to immune molecular mechanism study on head smut.

\section{Acknowledgements}

This work was financially supported by Liaoning Natural Science Foundation (2014027018), National Natural Science Foundation (31301842) and Cultivation Plan for Youth Agricultural Science and Technology Innovative Talents of Liaoning Province (2014043). 


\section{References}

[1] Dodman, R.L., Obst, N.R., Henzell, R.G. (1985) Races of sorghum head smut (Sporisorium reilianum) in South-East Queensland. Australasian Plant Pathology, 14(2):45.

[2] Leslie, J.F. (2013) Sorghum and Millets Diseases. Wiley-Blackwell, VII47.

[3] Poland, J.A., Bradbury, P.J., Buckler, E.S., Nelson, R.J. (2011) Genome-wide nested association mapping of quantitative resistance to northern leaf blight in maize. proceedings of the national academy of sciences of the united states of America, 108(17): 6893-6898.

[4] Prom, L.K., Perumal, R., Erattaimuthu, S., Erpelding, J.E., Montes-Garcia, N., Odvody, G., Greenwald, C., Jin, Z., Frederiksen, R., Magill, C. (2011) Virulence and molecular genotyping studies of Sporisorium reilianum isolates in sorghum. Plant Disease, 95: 523-529.

[5] Herrera, J.A., Vallejo, A. B. (1986) Distribution of races of head smut (Sporisorium reilianum) in the northeast and southwest areas of Mexico. Sorghum Newsletter, 29: 86.

[6] Yang Huiyong, Wang Huayun, Zhao Wenbo, Wang Rui, Zhan Pengjie, Yu Jizhen, Zhang Fuyao. (2014) The identification of resistance sources to head smut in sorghum and the analysis of genetic diversity. Journal of Shanxi Agricultural Sciences, 42(12):1252-1255.

[7] Frederiksen, R.A., Odvody, G.N. (1986) Compendium of Sorghum Diseases. St Paul: American Phytopathology Society, 17-18.

[8] Zou Jianqiu, Li Yueying, Zhu Kai, Wang Yanqiu. (2010) Study on Inheritance and Molecular Makers of Sorghum Resistance to Head Smut Physiological Race 3. Agricultural Sciences in China, 2010, 43(4): 713-720.

[9] Jones, J.D.G. and Dangl, J.L. (2006) The plant immune system. Nature, 444: 323-329.

[10] Hematy, K., Cherk, C., Somerville, S. (2009) Host-pathogen warfare at the plant cell wall. Current Opinion in Plant Biology, 12(4): 406-413.

[11] Paterson, A.H., Bowers, J.E. (2009) The Sorghum bicolor genome and the diversification of grasses. Nature, 457: 551-556. 